\title{
Implementasi Fuzzy Inference System Untuk Menentukan Tingkat Kriminalitas Di Kota Batam
}

\author{
Sestri Novia Rizki ${ }^{1}$, Handra Tipa ${ }^{2}$ \\ ${ }^{1,2}$ Program studiTeknik Informatika, Fakultas Teknik,Universitas Putera Batam \\ Jl.R.Soeprapto, Tembesi, Kota Batam, Sagulung \\ Email: ${ }^{1}$ noviasestri@gmail.com, ${ }^{2}$ handratipa@gmail.com
}

\begin{abstract}
Abstrak
Kriminalitas merupakan sebuah perbuatan meyimpang serta merugikan banyak orang.Pada tahun 2017 perekonomian Kota Batam menurun, sehigga banyak perusahaan yang tutup dan menyebabkan tingkat pengangguran meningkat.Kejahatan yang marak terjadi saat ini seperti pembegalan, pencopetan, Penipuan, dan penjampretan tanpa belas kasihan bahkan menyebabkan korban meninggal dunia.Contoh kejahatan yang sering terjadi berupa pembegalan dan penjamretan pada daerah tamiang, banyak korban yang berjatuhan, pelaku Tidak segan melukai bahkan menghilangkan nyawa korbannya. Faktor utama penyebab kriminalitas seperti tingkat kesenjangan social, pendidikan, pendidikan, pergaulan, PengangguranLowongan Pekerjaan serta pendidikan sehingga banyak hal yang membuat tingkat kriminalitas yang tinggi di kota Batam. Tujuan penelitian ini yaitu untuk mengetahui tingkat kriminalitas di kota Batam, serta sabagai pembelajaran bagi penduduk batam sehingga terhindar dari kejahatan. Metode yang digunakan menggunakansystem max-mix atau logika sugeno, langkah kerja metode fuzzy ada empat, yang pertama pembentukan himpunan fuzzy, yang kedua aplikasi fungsi implikasi yang ketiga komposisi aturan dan yang keempat adalah defuzzifikasi.Fokus penelitian ini berupa 1.Menentukan Tingkat kriminalitas 2.Penyebab kriminalitas 3.Menggunakan metode sugeno dan aplikasi matlab untuk menyelesaikan hasil penelitian. Penelitian ini menghasilkan system mendukung keputusan berupa hasil akhir sebesar 0.72 berada pada posisi Output dengan nilai keputusan tingkat kriminalitas tinggi di Kota Batam.
\end{abstract}

Katakunci: Kriminalitas, Fuzzy logic, Metode Sugeno, Matlab, FIS.

\begin{abstract}
Crime is an act that deviates and harms many people. In 2017 the economy of Batam City declined so that many companies closed and caused the unemployment rate to increase. Crimes are rife at this time, such as hijacking, pickpocketing, fraud, and mugging without mercy, even causing death. Examples of crimes that often occur in the form of kidnapping and mugging in the Tamiang area, many victims have fallen, the perpetrators do not hesitate to hurt or even kill the lives of their victims. The main factors were causing crime such as the level of social inequality, education, relationships, Job Vacancy Unemployment and education so that many things that make a high crime rate in the city of Batam. The purpose of this study is to determine the level of crime in the city of Batam, as well as learning for residents of Batam, is avoid way. The method used uses the max-mix system or Sugeno logic, there are four steps in the fuzzy process, the first is the formation of the fuzzy set, the second is the application of the implication function, the third is the composition of the rules, and the fourth is defuzzification. The scope of this research is 1. They are using the level of crime 2. Cause of crime 3. They are using the Sugeno method and the application of Matlab to complete the research results. This research results offence ina system was supporting the decision in the form of the final They are eISSN: 2477-3255, pISSN: 2086-4884

https://doi.org/10.31849/digitalzone.v10i2. 3090
\end{abstract}


determining of 0.72 is in the Output position with a high crime rate decision value in Batam City.

Keywords: Criminality, Fuzzy logic, Sugeno Method, Matlab, FIS.

\section{Pendahuluan}

Kejahatan atautindak kriminal merupakan salah satu bentuk dari perilaku menyimpang yang selalu ada dan melekat pada tiap bentuk masyarakat. Perilaku menyimpang itu merupakan suatu ancaman yang nyata atau ancaman terhadap norma-norma sosial yang mendasari kehidupan atau keteraturan sosial,dapat menimbulkan ketegangan individual maupun ketegangan-ketegangan sosial,dan merupakan ancaman riil atau potensi bagi berlangsungnya ketertiban sosial. Kejahatan di samping masalah kemanusiaan juga merupakan masalah sosial, tidak hanya merupakan masalah bagi masyarakat tertentu,tetapi juga menjadi masalah yang dihadapi oleh seluruh masyarakat di dunia. Contoh kejahatan yang terjadi seperti pembunuhan dengan motif pencurian yang terjadi di daerah bengkong, Pemerkosaan yang terjadi di putri Hijau Batu Aji, penjampretan yang terjadi di daerah Punggur dan pembegalan yang terjadi di daerah tamiang. Barita Kriminalitas pasti terjadi setiap hari. Hal ini bisa dilihat dari berita Koran,internet dan TV Batam. Permasalahan yang sering terjadi saat ini banyak penduduk batam tidak menyadari tingkat kriminalitas yang terjadi , mengetahui ciri ciri penyebab kriminalitas, serta kurang kesadaran penduduk batam dalam menjaga diri dari tindakan kriminalitas.

Tujuan utama penelitian ini menentukan tingkat kriminalitas di kota Batam, sabagai pembelajaran bagi penduduk untuk berhati hati agar terhindar dari Tindakan kejahatan,dan acuan dalam penentuan persentase nilai angka kejahatan di Kota Batam.Saat ini pihak kepolisian telah memberi peringatan agar lebih waspada dalam menghindari kejahatan seperti tidak berpergian sendiri bagi wanita ditempat yang sepi, tidak keluar malam, dan dilarang berpakaian mencolok serta memakai perhiasan yang memencing tindakan kriminalitas. Saat ini Polresta Barelang sudah melakukan razia pada siang dan malam hari agar kota Batam terhindar dari tindakan kejahatan. Agar terhindar dari tindakan kejahatan penduduk harus selalu waspada dan mengetahui gerak gerik yang mencurigakan agar terhindar dari tindakan kejahatan. Maka penelitian ini menggunakan sebuah pendekatan metode Sugeno fuzzy untuk membantu penduduk batam dalam mengantisipasi kejahatan yang terjadi Di Kota Batam. Menurut hasil penelitin gilang, bandi dan arwan yang berjudul pemetaan daerah rawan kriminalitas di wilayah hokum POLTABES semarang tahun 2013 dengan mengunakan metode Clustering menjelaskan bahwa di kota semarang cenderung rawan disekitaran pusat kota sedangkan wilayan pinggir yang relative rendah kepadatan penduduknya kriminalitas nya cendrung lebih aman. Intensitas dari kriminalitas itu sendiri paling tinggi pada waktu larut malam [1]. Berikutnya Penelitian yang dilakukan Panji AS dan Vita $\mathrm{R}$ yang berjudul Permodelan persentasi kriminalitas dan faktor-faktor yang mempengaruhi Di jawa timur dengan pendekatan Georaphically weighted Regression. darihasil penelitian ini didapatkan bahwa adanya pengaruh spasial dalam pemodelan persentase kriminalitas di Jawa Timur. Pemilihan pembobot dilakukan dengan cara memilih pembobot yang memiliki nilai AIC terkecil yaitu fix gaussian. Wilayah yang berdekatan cenderung memiliki kesamaan faktor-faktor yang mempengaruhi persentase kriminalitas di Jawa Timur.Variabel kepadatan penduduk dan persentase penduduk migran berpengaruh signifikan pada sebagian besar kabupaten/kota di Jawa Timur. Model GWR menghasilkan R2 sebesar 86,95 persen lebih besar dari model OLS yaitu 54,1 persen [2].Berikut nya juga ada penelitian yang berjudul analisis jalur faktor-faktor penyebab kriminalitas di kota Manado pada penelitian ini menjelaskan bahwa pengaruh lansung dari kriminalitas adalah 
jumlah penduduk dan pengangguran sedangkan banyaknya industry dan keiskinan berpengaruh secara tidak lasung terhadap kriminalitas[3].

Metodologi ini dapat diterapkan pada perangkat keras, perangkat lunak, atau kombinasi keduanya. Dalam logika klasik dinyatakan bahwa segala sesuatu bersifat biner, yang artinya adalah hanya mempunyai dua kemungkinan, "Ya atau Tidak", "Benar atau Salah", "Baik atau Buruk", dan lain lain. Oleh karena itu, semua ini dapat mempunyai nilai keanggotaan 0 atau 1.Akan tetapi, dalam logika fuzzy memungkinkan nilai keanggotaan berada di antara 0 dan 1 . Artinya, bisa saja suatu keadaan mempunyai dua nilai "Ya dan Tidak", "Benar dan Salah", "Baik dan Buruk" secara bersamaan, namun besar nilainya tergantung pada bobot keanggotaan yang dimilikinya[4]. Titik awal dari konsep modern mengenai ketidakpastian adalah paper yang dibuatoleh Lofti A Zadeh (1965), dimana Zadeh memperkenalkan teori yangmemiliki obyekobyek dari himpunanfuzzy yang memiliki batasan yang tidakpresisi dan keanggotaan dalamhimpunan fuzzy, dan bukan dalambentuk logika benar (true) atau salah(false), tapi dinyatakan dalam derajat(degree). Konsep seperti ini disebutdengan Fuzziness dan teorinyadinamakan Fuzzy Set Theory.Fuzziness dapat didefinisikan sebagai logika kabur berkenaan dengan semantik dari suatu kejadian, fenomena atau pernyataan itu sendiri. Seringkali ditemui dalampernyataan yang dibuat oleh seseorang, evaluasi dan suatu pengambilan keputusan[5]. [6]Logika Fuzzy adalah suatu cara yang tepat untuk memetakan suatu ruang input ke dalam suatu ruang output. Alasan digunakannya Logika Fuzzy adalah 1.Sistem fuzzy mudah dan fleksibel 2.Memiliki konsep yang sederhana sehingga mudah dipahami oleh user 3.Memiliki tolerasi pada data data 4.Membuat suatu system yang lebih kompleks 5 Logika Fuzzy dapat membangun dan mengaplikasikan pengalaman- pengalaman para pakar secara langsung tanpa harus melalui proses pelatihan. 6.Gampang dipahami sehingga tidak perlu melakukan pelatihan terlebih dahulu 7.Mampu bekerja sama dengan baik 8.Berdasarkan bahasa alami dan mudah dimengerti oleh manusia.

Pada himpunan tegas (crisp), nilai keanggotaan suatu intem x dalam suatu himpunan A, yang sering ditulis dengan $\mu \mathrm{A}[\mathrm{x}]$ memiliki dua kemungkinan yaitu berupa angka 1 dan 0[7].Fuzzy Rule-Based Systems (FRBSs) bahasa linguistic dengan menggunakan Fuzzy Inference System metode Mamdani. Hasil dari penelitian ini membuktikan kegunaan dari FRBSs bahasa linguistic dalam sebuah perkembangan dan masalah signifikan dalam data mining seperti klasifikasi dataset yang tidak seimbang dan khusus untuk mereka dengan tingkat ketidakseimbangan yang tinggi. Secara khusus, penelitian ini menunjukkan perilaku yang baik dari FRBSs hirarki linguistic, meningkatkan klasifikasi kinerja di daerah yang tumpang tindih antara minoritas dan mayoritas kelas dan mengungguli pohon keputusan C4.5 [8].

Masalah ini dan mengenalkan algoritma baru yang disebut FuzzySolidLinguisticItemsetMining (FSLIM) untuk menemukan SolidLinguisticItemsets (SLIs) dalam dataset kuantitatif. SLI adalah konsep baru yang diperkenalkan di sini sebagai bagian penting dari solusi yang disajikan dalam makalah ini. Metode yang diusulkan terdiri dari dua tahap. Pada fase pertama, teori himpunan fuzzy digunakan untuk mentransformasikan setiap nilai kuantitatif ke item linguistik; Dan pada fase kedua, semua SLI diekstraksi. Akhirnya, efisiensi FSLIM dibandingkan dalam hal waktu eksekusi, skalabilitas dan jumlah pola yang sering terjadi dengan dua pendekatan klasik pada dataset sintetis. Pendekatan yang diusulkan juga diterapkan pada kumpulan data Urban Masyhad yang sebenarnya untuk menggambarkan kemampuan FSLIM dalam menemukan pengetahuan tersembunyi yang tidak dapat diekstraksi dengan metode tradisional[9]. Model fuzzy / linguistik sejak awal dikembangkan dengan menggunakan logika formal. Namun, formulasi asli berdasarkan versi predikat dari, disebut demikian, logika fuzzy dengan sintaks yang dievaluasi ternyata tidak memuaskan secara rapi. Perumusan baru yang

eISSN: 2477-3255, pISSN : 2086-4884

https://doi.org/10.31849/digitalzone.v10i2. 3090 
menggunakan bahasa logika fuzzy matematika tingkat tinggi jauh lebih sesuai dan transparan[10].

Meskipun sudah banyak penelitian yang sudah dilakukan, akan tetapi, penelitian yang mengkaji tentang tingkat kriminalitas yang dianalisa dengan menggunakan Logika Fuzzy metode Sugeno serta cara penanggulangan tindakan kriminalitas agar terhindar dari tindakan kejahatan yang terjadi belum ditemukan. Oleh karena itu, penelitian ini berbeda dengan penelitian fuzzy yang sudah ada sebelumnya. Hal ini dilihat dari variabel dan data yang ditemukan dalam wawancara langsung bersama nara sumber dari Kepolisian. Data yang diperolehtersebut sesuai dengan keadaan yang terjadi pada penduduk kota Batam saat ini.

Berdasarkan hasil analisa data, penelitian ini menghasilkan sebuah nilai output dengan persentasi tingkat kriminalitas. Sistem yang digunakan di Kota Batam masih belum lengkap sehingga kebanyakan orang terlalu cuek dalam menjaga diri dari kejahatan.Melalui penelitian ini, diharapkan kepada seluruh penduduk batam bisa memahami informasi yang sangat berguna sehingga terdindar dari tindakan kriminalitas. Jika penduduk bisa memahami informasi tentang tindakan ini maka kota Batam akan aman dan tidak akan ada lagi Koran yang berjatuhan akibat tindakan kejahatan.Sehingga Kota batam ini bisa dijadikan kota yang aman bagi penduduk, tidak terbatas untuk pergi keluar sendirian.

\section{Metode Penelitian}

Pada sebuah penelitian harus memiliki gambaran tentang penelitian yang akan dilaksanakan. Langkah langkah penelitian yang akan dilaksanakan diantaranya :

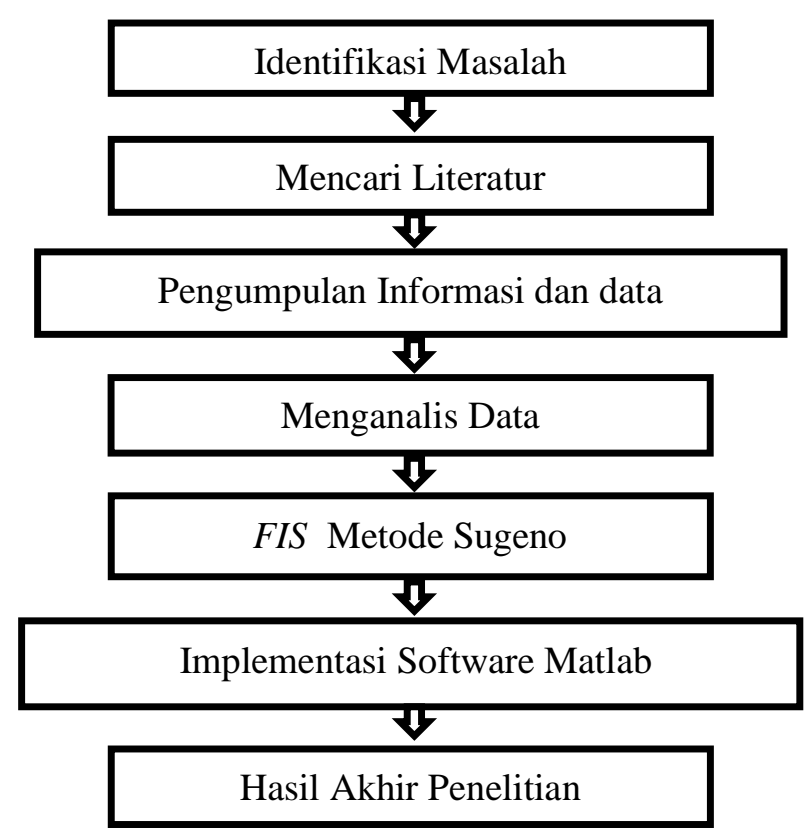

Keterangan :

Gambar 2. Desain Penelitian

1. Identifikasi Masalah

Mengidentifikasi masalah dari latar belakang masalah yang terjadi mengenai Tingkat Krimialitas di Kota Batam.

2. Mecari Literatur

Pempelajari buku-buku dan jurnal-jurnal referensi yang berhubungan dengan penelitian yang dilakukan. 
3. Pegumpulan informasi dan Data

Data dan informasi didapat melalui wawancara dan analisa dokumen dari pihak Polresta Barelang.

4. Menganalisa Data

Setelah data dan informasi didapatkan, penulis memilih dan mempersiapkan data-data tersebut untuk diolah dengan menggunakan indikator-indikator dari variabel penelitian.

5. FIS Metode Sugeno

Data yang telah dipersiapkan akan diolah menggunakan Fuzzy Inference System MetodeSugeno .

6. Implementasi Software Matlab

Implementasi data dilakukan dengan menggunakan bantuan software Matlab, dengan menggunakan fasilitas yang disediakan pada toolboxfuzzy. Setelah data di implementasikan dengan Matlab, data akan dianalisa kembali apakah data tersebut sesuai dengan ketentuan penulis.

7. Hasil Penelitian Penelitian

Hasil penelitian merupakan bagian akhir dari semua penelitian yang telah dilakukan dengan mendokumentasikan riset secara keseluruhan.

\section{Hasil dan pembahasan}

Konsep dasar dalam penelitian fuzzy harus jelas penetapan variabel input dan variabel output. Pada kasus ini memiliki 5 input dan 1 output, 5 variabel input yaitu Kesenjangan Ekonomi,Pergaula, ilmu pegetahuan, pengagguran, dan lowonga pekerjaan. Sedangkan variabel output terdiri dari tinggi dan rendah. Langkah awal penyelesaian masalah yaitu menentukan pembentukan himpunan dan fungsi keanggotaan dari masing masing variabel yang akan digunakan.

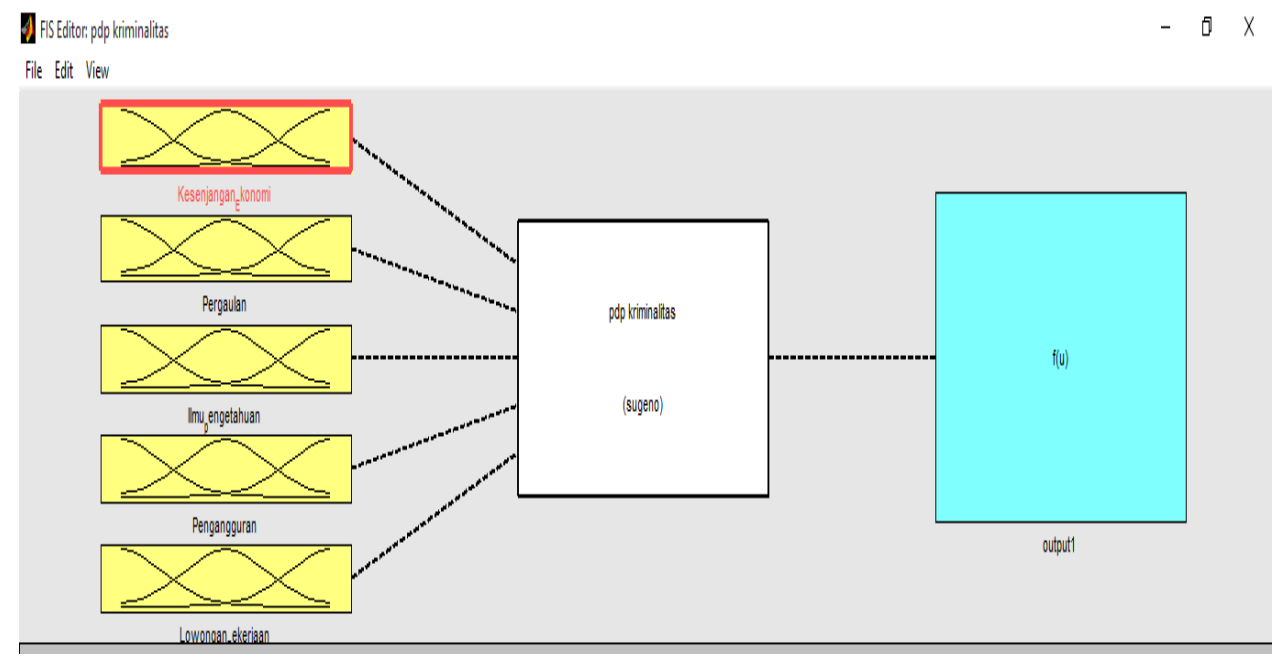

Gambar 3. Aliran Fuzzy

Dibawah ini merupakan gambaran awal dari table himpunan fuzzy serta semesta pembicaraan, anggka angka yang diperoleh berdasarkan logika fuzzy data yang didapatkan. 
Tabel 1. Himpunan Fuzzy

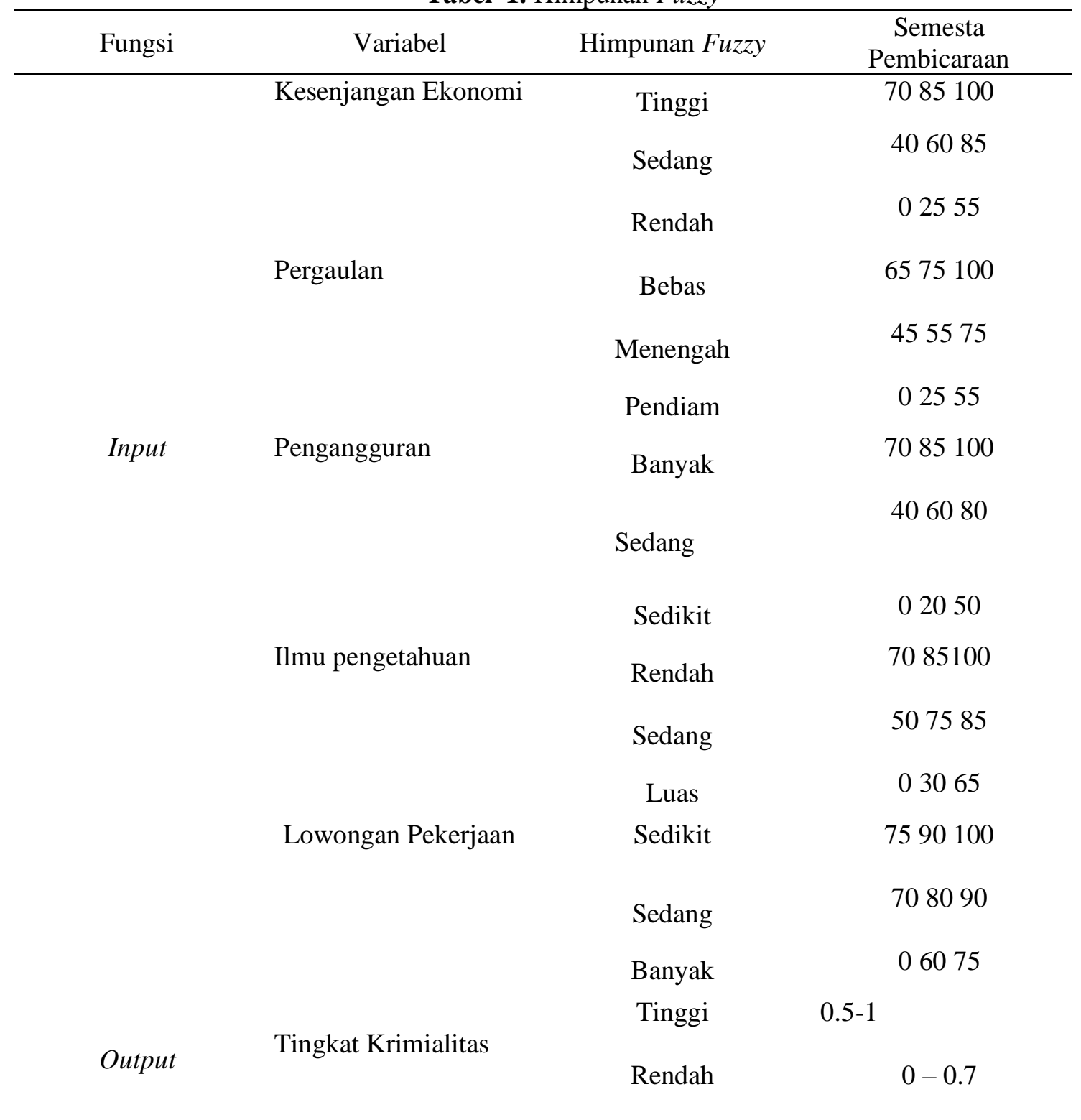

Dibawah ini akan di jelaskan masing masing variable input pada tingkat kriminalitas dikota Batam

1. Fungsi derajat keanggotaan variabel Kesenjagan Sosial

Kesenjangan sosial sering terjadi di lingkungan tempat tinggal, jika seseorang tidak bisa menahan diri maka ia akan terjerumus kedalam tindakan kriminalitas karena keadaan tidak sesuai dengan keinginan yang dimiliki. Sehingga tanpa berfikir panjang ingin memiliki sesuai tanpa menyesuaikan dengan kemampuan yang dimiliki.Pada kesenjangan sosial dibagai menjadi 3 bagian yaitu, rendah, sedang dan tinggi. Berikut gambar implementasi matlab: 


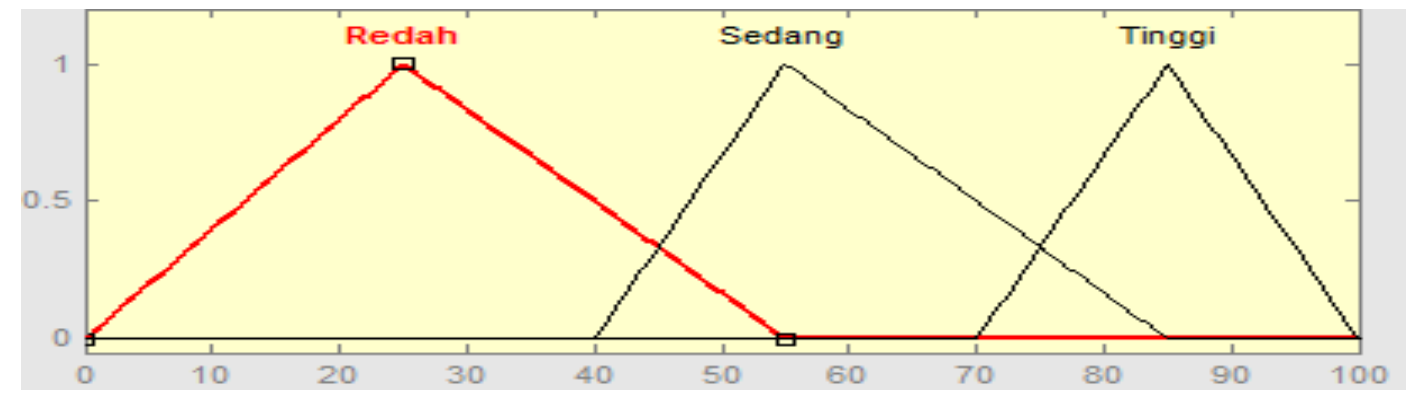

Gambar 4. Variabel Kesenjangan Ekonomi

$\mu$ Rendah $[x]=\left\{\begin{array}{cr}1 & x \leq 25 \\ \frac{55-x}{55-25} ; & 25 \leq x \leq 55 \\ 0 & x \geq 55\end{array}\right.$

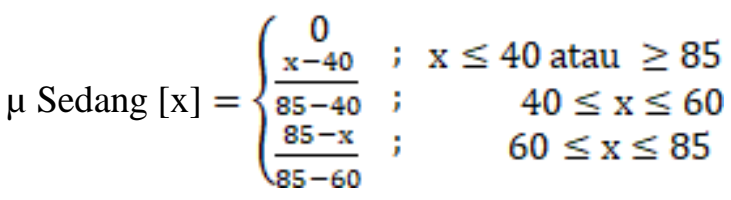

$\mu$ Tinggi $[x]=\left\{\begin{array}{cr}0 & x \leq 70 \\ \frac{x-70}{85-70} ; & 70 \leq x \leq 85 \\ 1 ; & 85 \leq x \leq 100\end{array}\right.$

2. Fungsi derajat keanggotaan variable Input Pergaulan

Pergauluan penting dalam kehidupan sehari hari, jika seseorang tidak pandai membatasi pergaulan maka ia akan terjerumus kedalam tindakan kriminalitas. Jika pergaulan yang sehat akan memiliki dampak yang positif namun jika pergaulan yang tidak sehat maka akan terjerus kedalam tindakan kejahatan. Pada variabel pergaulan dibagi menjadi tiga Bebas, menengah dan pendiam. Bentuk representasi nya adalah:

$\mu$ Pendiam $[x]=\left\{\begin{array}{cr}1 & x \leq 20 \\ \frac{20-x}{50-20 ;} ; & x \leq \leq 50 \\ 0 ; & x \geq 50\end{array}\right.$

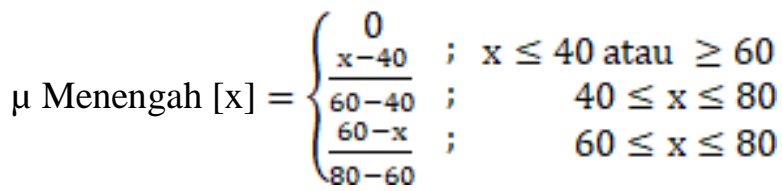

$\mu$ Bebas $[x]=\left\{\begin{array}{cr}0 & x \leq 70 \\ \frac{x-70}{85-70} ; & 70 \leq x \leq 85 \\ 1 & 85 \leq x \leq 100\end{array}\right.$ 


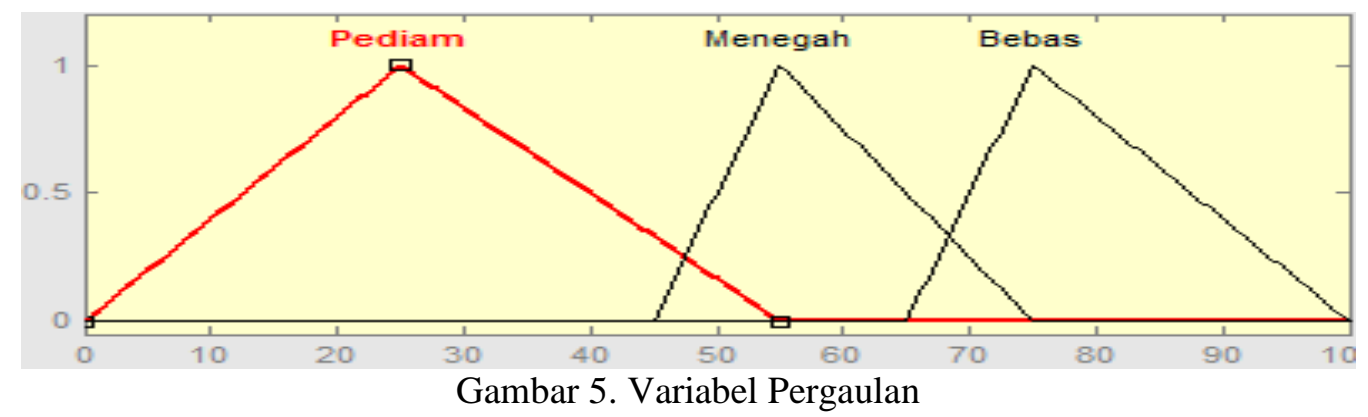

3. Fungsi derajat keanggotaan variabel Input Pengangguran

Pada saat ini kota batam memiliki pengangguran yang banyak sehingga banyak. Hal ini disebabkan oleh banyak nya PT yang tutup, sehingga untuk memenuhi kehidupan sehari hari banyak yang memiliki cara pintas untuk mendapatkan uang untuk menjalani hidupnya. Fungsi pengangguran dibagi menjadi 3 bagian yaitu sedikit, sedang dan banyak.Bentuk representasinya.

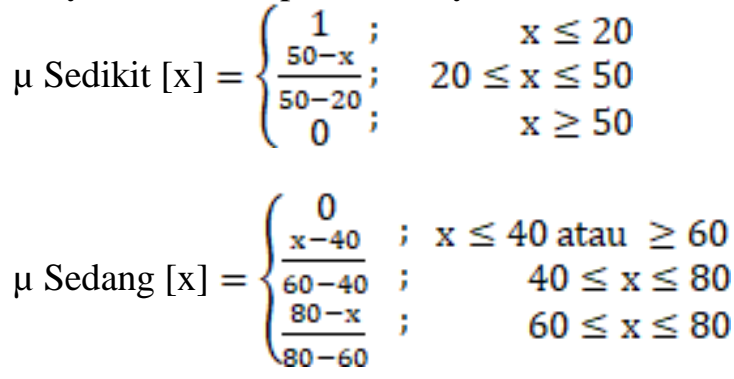

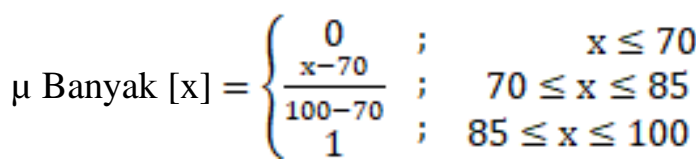

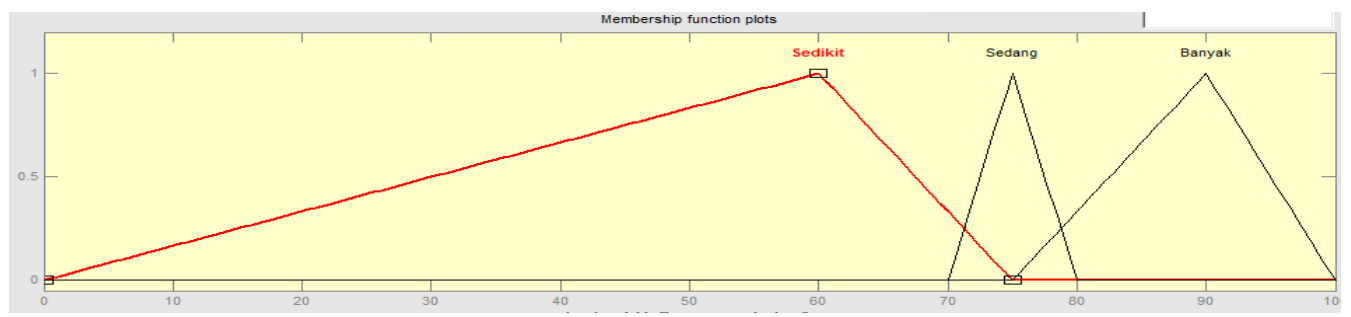

Gambar 6. Variabel Pengangguran

4. Fungsi derajat keanggotaan variabel Input Ilmu pengetahuan

Semakin tinggi pengetahuan seseorang makan akan semakin tinggi penelaran untuk melakukan sesuatu, begitu juga sebaliknya. Orang yang memiliki pengetahuan yang dalam akan berfikir jernis untuk melakukan sesuatu serta memikirkan dampat positif dan negatif setiap pekerjaan yang akan dilakukan. Ilmu pengetahuan dibagi menjadi 3 bagian yaitu sedikit, sedang dan luas Bentuk representasinya.

$\mu$ Sedikit $[x]=\left\{\begin{array}{cr}1 ; & x \leq 30 \\ \frac{30-x}{65-30} ; & 30 \leq x \leq 65 \\ 0 & x \geq 65\end{array}\right.$ 


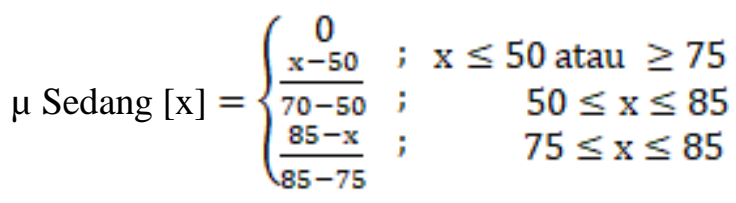

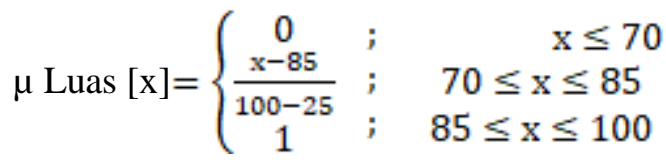

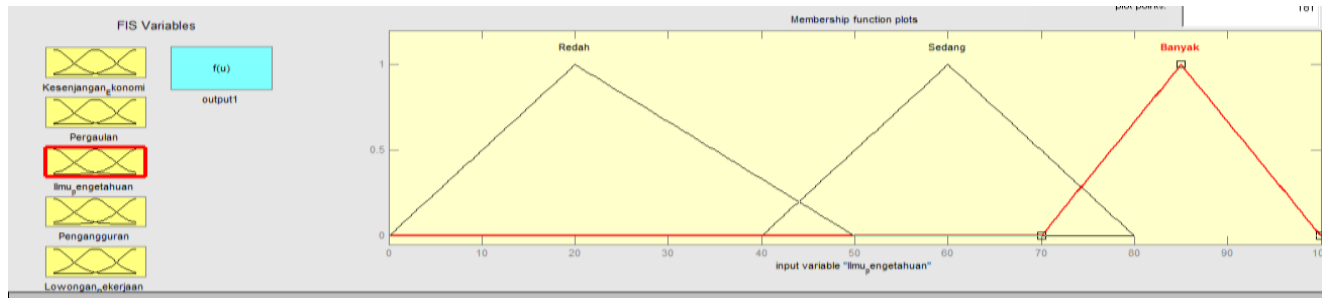

Gambar 7. Variabel Pengetahuan

5. Fungsi derajat keanggotaan variabel Lowongan Pekerjaan

Lowongan saat ini di kota batam sedikit, hal ini disebabkan karena banyak PT yang tutup dan pindah ke Negara luar, sehingga banyak kariawan yang di Phk Dan Tidak Memiliki Pekerjaan, Sehingga ada yang terjerumus kedalam tindakan criminal. Lowongan pekerjaan dibagi menjadi 3 bagian yaitu kecil,sedang, banyak Bentuk representasinya.

$\mu \operatorname{Kecil}[x]=\left\{\begin{array}{cr}1 ; & x \leq 60 \\ 60-x ; & 630 \leq x \leq 75 \\ 75-60 ; & x \geq 75\end{array}\right.$

$\mu$ Sedang $[x]=\left\{\begin{array}{cr}0 & x \leq 70 \text { atau } \geq 85 \\ \frac{x-70}{85-70} ; & 70 \leq x \leq 90 \\ \frac{90-x}{90-80} ; & 80 \leq x \leq 90\end{array}\right.$

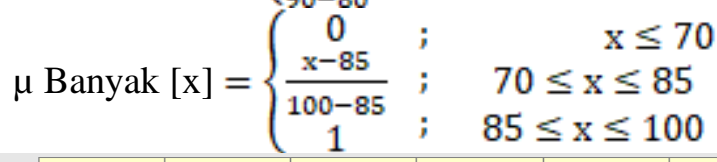

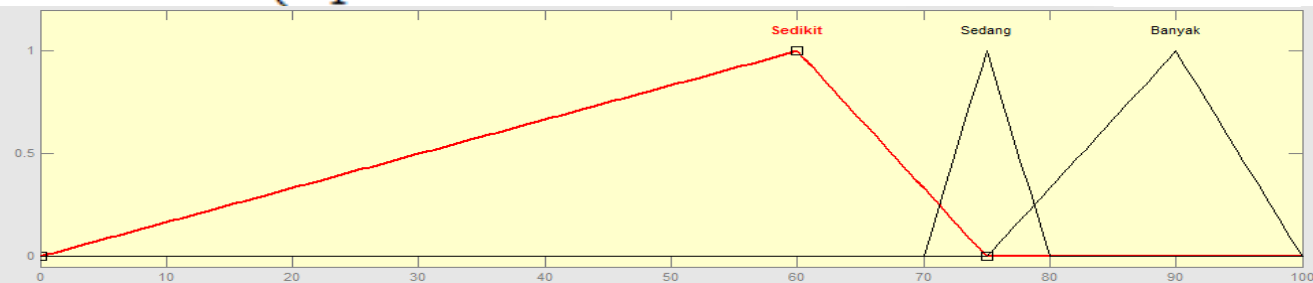

Gambar 8. Variabel Pekerjaan

Fungsi derajat keanggotaan linier turun digunakan untuk merepresentasikan himpunan fuzzy rendah dan fungsi derajat keanggotaan linier naik untuk himpunanfuzzy tinggi.Fungsi derajat keanggotaan segitiga digunakan untuk merepresentasikan himpunan fuzzy normal.Bentuk representasinya. 


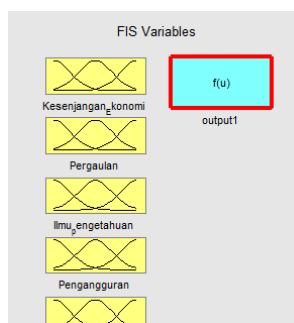

Membership function plots

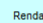

Gambar 9. Variabel Keputusan

Diwabah ini hasil rule -rule dari perkalian matriks dan hasil combinasi :

Tabel 2.Rule Tingkat kriminalitas

\begin{tabular}{ccccccc}
\hline Rule & $\begin{array}{c}\text { Kesenjang } \\
\text { an Sosial }\end{array}$ & Pergaulan & Pengagguran & $\begin{array}{c}\text { Ilmu } \\
\text { Pegetahua }\end{array}$ & $\begin{array}{c}\text { Lowogan } \\
\text { Pekerjaan }\end{array}$ & Keputusan \\
\hline R1 & Sedang & Bebas & Banyak & Rendah & Sedang & Tinggi \\
R2 & Sedang & Bebas & Banyak & Sedang & Sedang & Tinggi \\
R3 & Sedang & Bebas & Banyak & Tinggi & Sedang & Tinggi \\
R4 & Sedang & Bebas & Sedang & Rendah & Sedang & Tinggi \\
R5 & Sedang & Bebas & Sedang & Sedang & Sedang & Tinggi \\
R6 & Sedang & Bebas & Sedang & Tinggi & Sedang & Tinggi \\
R7 & Sedang & Bebas & Sedikit & Rendah & Sedang & Tinggi \\
R8 & Sedang & Bebas & Sedikit & Sedang & Sedang & Tinggi \\
R9 & Sedang & Bebas & Sedikit & Tinggi & Sedang & Tinggi \\
R10 & Tinggi & Pendiam & Banyak & Rendah & Banyak & Tinggi \\
R11 & Tinggi & Pendiam & Banyak & Sedang & Banyak & Tinggi \\
R12 & Tinggi & Pendiam & Banyak & Tinggi & Banyak & Tinggi \\
R13 & Tinggi & Pendiam & Sedang & Rendah & Banyak & Tinggi \\
R14 & Tinggi & Pendiam & Sedang & Sedang & Banyak & Tinggi \\
R15 & Tinggi & Pendiam & Sedang & Tinggi & Banyak & Tinggi \\
\hline & & & & & & \\
\hline
\end{tabular}

\section{Pengujian 1}

Input $:$ Kesenjangan Sosial $=75$, Pergaulan $=40$, Pengangguran $=49$, Ilmu Pengetahuan $=39$, Lowongan Pekerjaan $=68$. Hasil dari perhitungan derjat keanggotaan fuzzy.

a.

Kesenjangan Sosial, terdiri dari 3 himpunan fuzzy, yaitu Rendah, sedang, dan Tinggi. Jika diketahui Kesenjangan Sosial memiliki nilai input $\mathrm{x} 75$ maka

$$
\begin{aligned}
\mu \text { Tinggi }[75] & =(\mathrm{c}-\mathrm{x}) /(\mathrm{c}-\mathrm{b}) \\
& =(85-75) /(85-55) \\
& =10 / 30 \\
& =0,333
\end{aligned}
$$




$$
\begin{aligned}
\text { usedang }[75] & =(\mathrm{x}-\mathrm{a}) /(\mathrm{b}-\mathrm{a}) \\
& =(75-40) /(55-40) \\
& =35 / 15 \\
& =0,42 \\
\mu \operatorname{Rendah}[75] & =0
\end{aligned}
$$

b.

Pendiam, Menengah, dan Bebas. Jika dike sebesar x 40, maka

$$
\begin{aligned}
\mu \text { Pendiam }[40] & =(\mathrm{c}-\mathrm{x}) /(\mathrm{c}-\mathrm{b}) \\
& =(55-40) /(55-25) \\
& =15 / 30 \\
& =0,5
\end{aligned}
$$

$\mu$ Menengah $[40]=0$

$\mu$ Bebas $[40]=0$

c. Pengangguran, Dibagi menjadi, yaitu sedikit, sedang, dan banyak, Jika diketahui pengangguran mempunyai nilai input sebesar x49, maka

$$
\begin{aligned}
\text { Msedikit }[49] & =(\mathrm{c}-\mathrm{x}) /(\mathrm{c}-\mathrm{b}) \\
& =(65-49) /(45-25) \\
& =15 / 20 \\
& =0,75 \\
\mu \text { sedang }[49] & =0 \\
\mu \text { banyak }[49] & =0
\end{aligned}
$$

d. Ilmu Pengetahuan, dibagi menjadi, yaitu Kecil, sedang, dan Banyak. Jika diketahui Ilmu Pengetahuan memiliki nilai input sebesar x39, maka

$$
\begin{aligned}
\mu r K e c i l[39] & =(c-x) /(c-b) \\
& =(50-39) /(5020) \\
& =(11 / 30) \\
& =0,36 \\
\mu \operatorname{sedang}[39] & =0 \\
\mu \text { Banyak }[39] & =0
\end{aligned}
$$

e.

Lowongan pekerjaan, dibagi menjadi, yaitu Kecil, sedang, dan Banyak. Jika diketahui Lowongan pekerjaan memiliki nilai input sebesar x68, maka

$$
\begin{aligned}
\mu r K e c i l[68] & =(\mathrm{c}-\mathrm{x}) /(\mathrm{c}-\mathrm{b}) \\
& =(75-68) /(75-60) \\
& =(7 / 15) \\
& =0,46 \\
\mu \operatorname{sedang}[39] & =0 \\
\mu \text { Banyak }[39] & =0
\end{aligned}
$$




\section{Implikasi}

Input $:$ Kesenjangan Sosial $=75$, Pergaulan $=40$, Pengangguran $=49$, Ilmu Pengetahuan $=39$, Lowongan Pekerjaan $=68$. Hasil dari perhitungan derjat keanggotaan fuzzy.

a.

Kesenjangan Sosial, terdiri dari 3

himpunan fuzzy, yaitu Rendah, sedang, dan Tinggi. Jika diketahui Kesenjangan Sosial memiliki nilai input x 75 maka

$$
\begin{aligned}
\mu \text { Tinggi }[75] & =(\mathrm{c}-\mathrm{x}) /(\mathrm{c}-\mathrm{b}) \\
& =(85-75) /(85-55) \\
& =10 / 30 \\
& =0,333 \\
\mu \text { sedang }[75] & =(\mathrm{x}-\mathrm{a}) /(\mathrm{b}-\mathrm{a}) \\
& =(75-40) /(55-40) \\
& =35 / 15 \\
& =0,42 \\
\mu \text { Rendah }[75] & =0
\end{aligned}
$$

b.

Pendiam, Menengah, dan Bebas. Jika diketahui Pergaulan memiliki nilai input sebesar x 40, maka

$$
\begin{aligned}
\mu \text { Pendiam }[40] & =(\mathrm{c}-\mathrm{x}) /(\mathrm{c}-\mathrm{b}) \\
& =(55-40) /(55-25) \\
& =15 / 30 \\
& =0,5
\end{aligned}
$$

$\mu$ Menengah $[40]=0$

$\mu$ Bebas $[40]=0$

c.

Pengangguran, Dibagi menjadi, yaitu sedikit, sedang, dan banyak, Jika diketahui pengangguran mempunyai nilai input sebesar x49, maka

$$
\begin{aligned}
\text { Msedikit }[49] & =(\mathrm{c}-\mathrm{x}) /(\mathrm{c}-\mathrm{b}) \\
& =(65-49) /(45-25) \\
& =15 / 20 \\
& =0,75 \\
\mu \text { sedang }[49] & =0 \\
\mu \text { banyak }[49] & =0
\end{aligned}
$$

d.

Ilmu Pengetahuan, dibagi menjadi, yaitu Kecil, sedang, dan Banyak. Jika diketahui Ilmu Pengetahuan memiliki nilai input sebesar x39, maka

$$
\begin{aligned}
\operatorname{\mu rKecil}[39] & =(\mathrm{c}-\mathrm{x}) /(\mathrm{c}-\mathrm{b}) \\
& =(50-39) /(5020) \\
& =(11 / 30) \\
& =0,36 \\
\mu \operatorname{sedang}[39] & =0 \\
\mu \text { Banyak[39] } & =0
\end{aligned}
$$


e. Lowongan pekerjaan, dibagi menjadi, yaitu Kecil, sedang, dan Banyak. Jika diketahui Lowongan pekerjaan memiliki nilai input sebesar x68, maka

$$
\begin{aligned}
\mu r K e c i l[68] & =(\mathrm{c}-\mathrm{x}) /(\mathrm{c}-\mathrm{b}) \\
& =(75-68) /(75-60) \\
& =(7 / 15) \\
& =0,46 \\
\mu \operatorname{sedang}[39] & =0 \\
\mu \text { Banyak }[39] & =0
\end{aligned}
$$

\section{Implikasi}

a. R1

If Kesenjangan Sosial RENDAH, or pergaulan PENDIAM, or Pegangguran BANYAK, or Ilmu Pengeahuan RENDAH, or Lowongan pekerjaan SEDIKIT then Hasil Keputusan TINGGI.

$$
\begin{aligned}
\alpha_{1}= & \text { Kesenjangan Sosial Rendah } \square \mu_{\text {pergaulan pendiam }} \square \mu_{\text {Pengangguran Banyak }} \square \mu_{\text {Ilmu pengetahuan }} \\
& \operatorname{rendah~} \square \mu_{\text {Lowongan Pekerjaan Sedikit }} \square \mu_{\text {Tingkat Kriminalitas Tinggi }} \square \\
= & \max \left(\mu \text { Kesenjangan Sosial Rendah }[75] \square \mu_{\text {pergaulan pendiam }[40] \square}\right. \\
& \mu_{\text {Pengangguran Banyak }}[49] \square \mu_{\text {Ilmu }} \text { pengetahuan rendah }[39] \square \mu_{\text {Lowongan Pekerjaan Sedikit }} \\
& {[68] \square } \\
= & \text { max }((0 \cup 0,5 \cup 0 \cup 0,36 \cup 0,46) \\
& \text { Dari himpunan variabel hasil keputusan } \\
\mathrm{z}_{1}=1 &
\end{aligned}
$$

b. $\mathrm{R} 2$

If Kesenjangan Sosial RENDAH, or pergaulan PENDIAM, or Pegangguran BANYAK, or Ilmu Pengeahuan SEDANG, or Lowongan pekerjaan SEDIKIT then Hasil Keputusan TINGGI.

$$
\begin{aligned}
& \alpha_{2}=\text { Kesenjangan Sosial Rendah } \square \mu_{\text {pergaulan pendiam }} \square \mu_{\text {Pengangguran Banyak }} \square \mu_{\text {Ilmu pengetahuan }} \\
& \text { Sedang } \square \quad \mu_{\text {Lowongan Pekerjaan Sedikit }} \square \mu_{\text {Tingkat Kriminalitas Tinggi }} \square \\
& =\max \left(\mu \text { Kesenjangan Sosial Rendah }[75] \square \mu_{\text {pergaulan pendiam }[40] \square}\right. \\
& \mu_{\text {Pengangguran Banyak }}[49] \square \mu_{\text {Ilmu }} \text { pengetahuan rendah }[39] \square \mu_{\text {Lowongan Pekerjaan Sedikit }} \\
& =\max ((0 \cup 0,5 \cup 0 \cup 0 \cup 0,46)
\end{aligned}
$$

Dari himpunan variabel hasil keputusan

$\mathrm{z}=1$

c. R3

If Kesenjangan Sosial RENDAH, or pergaulan PENDIAM, or Pegangguran BANYAK, or Ilmu Pengeahuan TINGGI, or Lowongan pekerjaan SEDIKIT then Hasil Keputusan TINGGI

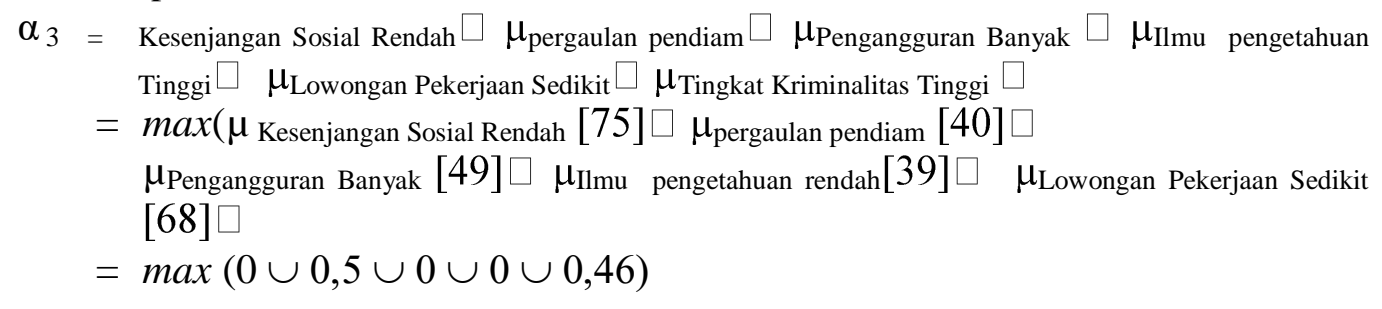


Dari himpunan variabel hasil keputusan

$\mathrm{z}_{3}=1$

Defuzzifikasi

$$
\begin{aligned}
& \left(\alpha^{1} z^{1}\right)+\left(\alpha^{2} * z^{2}\right)+\left(\alpha^{3} * z^{3}\right)+\left(\alpha^{4} * z^{4}\right)+\left(\alpha^{5} * z^{5}\right)+\left(\alpha^{6} * z^{6}\right)+ \\
& \left(\alpha^{7} * z^{7}\right)+\left(\alpha^{8} * z^{8}\right)+\left(\alpha^{9} * z^{9}\right)+\left(\alpha^{10} * z^{10}\right)+\left(\alpha^{11} * z^{11}\right)+\left(\alpha^{12} * z^{12}\right)+ \\
& \left(\alpha^{13} * z^{13}\right)+\left(\alpha^{14} * z^{14}\right)+\left(\alpha^{15} * z^{15}\right)+\left(\alpha^{16} * z^{16}\right)+\left(\alpha^{17} * z^{17}\right)+ \\
& z=\frac{\left(\alpha^{18} z^{18}\right)+\left(\alpha^{19} z^{19}\right)}{\alpha^{1}+\alpha^{2}+\alpha^{3}+\alpha^{4}+\alpha^{5}+\alpha^{6}+\alpha^{7}+\alpha^{8}+\alpha^{9}+\alpha^{10}+\alpha^{11}+\alpha^{12}+\alpha^{13}+\alpha^{14}} \\
& +\alpha^{15}+\alpha^{16}+\alpha^{17}+\alpha^{18}+\alpha^{19} \\
& (0,8 * 1)+(0,75 * 1)+(0,8 * 1)+(0,5 * 1)+(0,75 * 1)+(0,4 * 1)+ \\
& (0,4 * 1)+(0,4 * 1)+(0,5 * 1)+(0,75 * 1)+(0 * 1)+(0,4 * 0)+ \\
& z=\frac{(0,4 * 0)+(0 * 0)+(0 * 0)+(0,75 * 0)+(0 * 0)+(0,8 * 0)+(0 * 0)}{0,8+0,75+0,8+0,5+0,75+0,4+0,4+0,4+0,5+0,75+0+0,4+} \\
& 0,4+0+0+0,75+0+0,8+0 \\
& 0,8+0,75+0,8+0,5+0,75+0,4+0,4+0,4+0,5+0,75+0+ \\
& z=\frac{0+0+0+0+0+0+0+0}{0,8+0,75+0,8+0,5+0,75+0,4+0,4+0,4+0,5+0,75+0+0,4+} \\
& 0,4+0+0+0,75+0+0,8+0 \\
& z=\frac{6,05}{8,4} \\
& z=0,72
\end{aligned}
$$

Hasil akhir dari penelitian ini berupa output range nilai 0 sampai 1, yaitu keputusan berupa rendah dan tinggi. Jika nilai yang dimasukkan 0 sampai 0,50 maka nilai yang diperoleh berada pada posisi rendah, dan jika nilai 0,51 sampai 1 maka hasil yang akan diperoleh berupa nilai tinggi. Berdasarkan pengujian diatas maka dapat di ambil kesimpulan hasil akhir defuzification adalah tinggi.

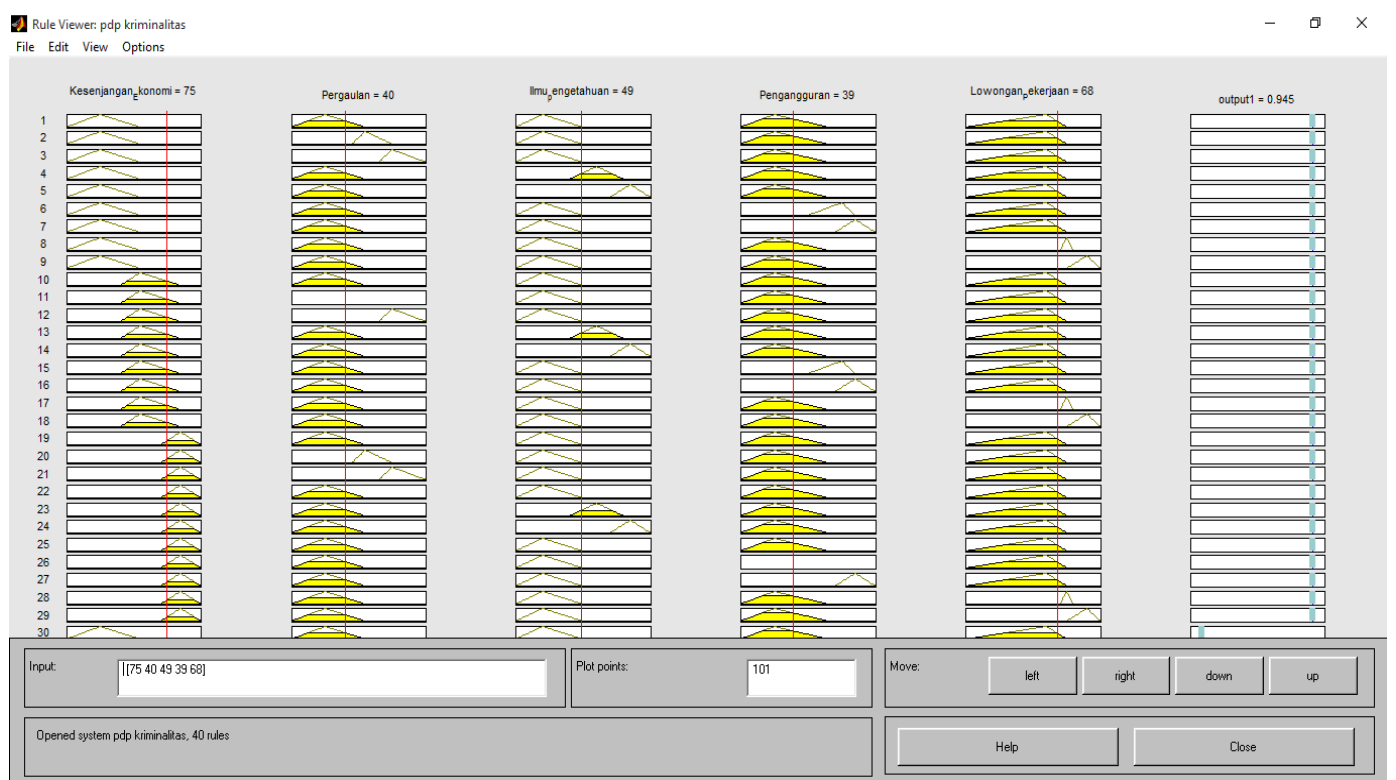

Gambar 10. Hasil Matlab 


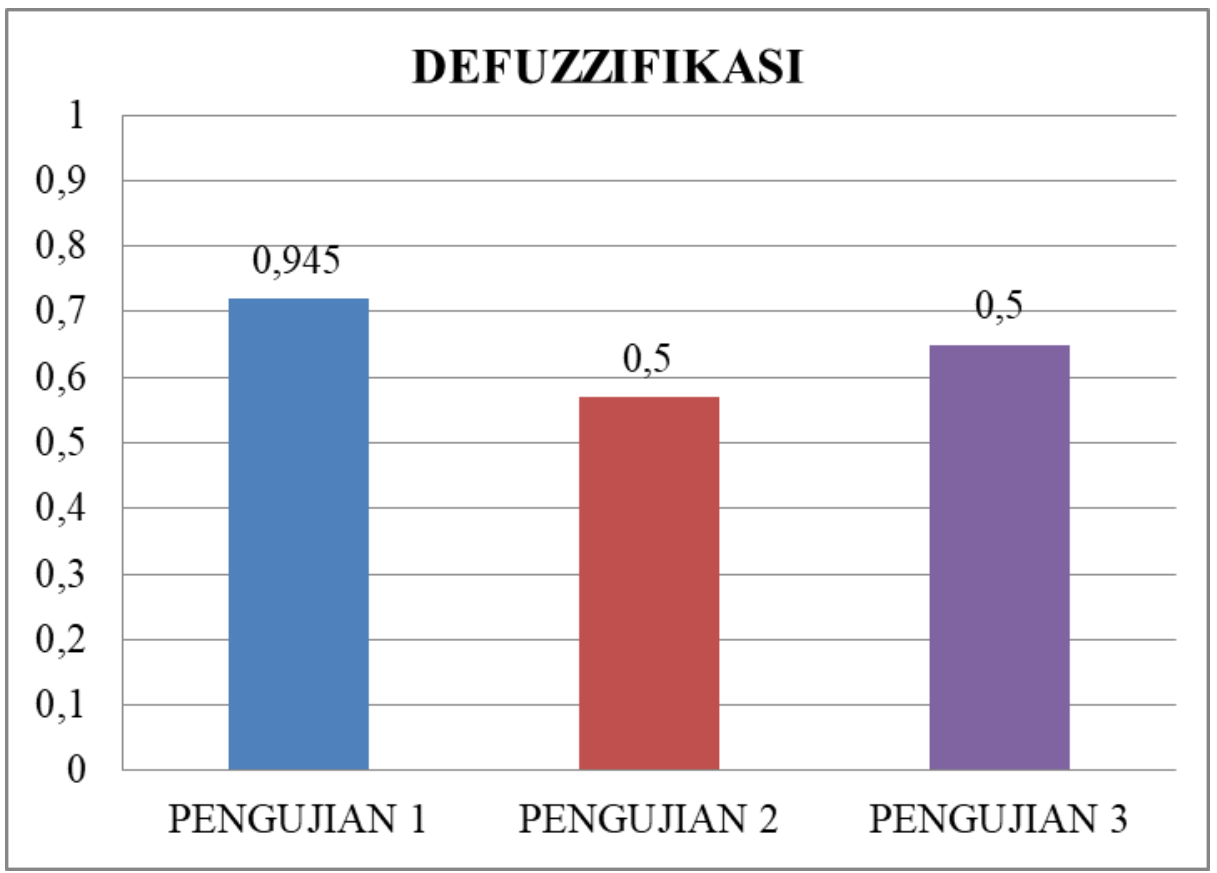

\section{Kesimpulan}

Gambar 11. Hasil Pengujian

Berdasarkan pembahasan penelitian dan analisa telah yang dilakukan, maka dapat disimpulkan bahwa; pertama, untuk menentukan hasil pengambilan keputusan dalam menentukan tingkat kriminalitas di Kota Batam memiliki 5 variabel input dan variabel output. Di dalam variabel input terdiri dara kesenjangan sosial, pergaulan, pengangguran, ilmu pengetahuan dan lowongan pekerjaan. Sedangkan pada variabel output berupa hasil keputusan Tinggi dan Rendah.Kedua, berdasarkan perhitungan manual dengan hasil pengujian system memiliki nilai yang tidak jauh berbeda dengan perhitungan matematika.Ketiga, dapat ditarik kesimpulan dari penelitian ini adalah logika fuzzy metode sugeno bisa diterapkan dalam pengambilan keputusan Tingkat kriminalitas di Kota Batam.Keempat, penelitian ini bisa dikembangkan untuk penelitian selanjutnya dengan menggabungkan beberapa pada logika Fuzzy.

\section{Daftar Pustaka}

[1] P. Daerah, r. Kriminalitas, d. Menggunakan, and m. Clustering, "jurnal geodesi undip januari 2015 jurnal geodesi undip januari 2015,” vol. 4, pp. 32-42, 2015.

[2] R. Gwr et al., "pemodelan persentase kriminalitas dan faktor- faktor yang mempengaruhi di jawa timur dengan pendekatan geographically weighted," vol. 3, no. 1, 2014.

[3] C. Y. Lumenta, j. S. Kekenusa, d. Hatidja, a. Jalur, and v. Eksogen, "path analysis of factors cause crime in manado," 2009.

[4] F. Aldyanto, j. T. Informatika, and f. T. Industri, "jurnal teknoif issn: 2338-2724 prediksi jumlah produksi roti menggunakan metode logika fuzzy ( studi kasus : roti malabar bakery ) jurnal teknoif issn : 2338-2724 metode sistem inferensi fuzzy," vol. 4, no. 2, pp. 59-65, 2016. 
[5] Y. Charolina, "sistem pendukung keputusan untuk menentukan pemberian bonus tahunan menggunakan metode fuzzy logic tipe mamdani ( studi kasus pada karyawan pt . Sunhope indonesia di jakarta )," vol. 12, pp. 42-53, 2016.

[6] T. Pangaribowo, "jurnal teknologi elektro, universitas mercu buana issn : 2086-9479 perancxangan simulasi kendali," vol. 6, no. 2, pp. 123-135, 2015.

[7] J. M. Infotama, d. Tetap, f. Ilmu, k. Universitas, and d. Bengkulu, "metode logika fuzzy tsukamoto dalam sistem pengambilan," vol. 9, no. 1, 2013.

[8] A. Fernández and f. Herrera, "linguistic fuzzy rules in data mining: follow-up mamdani fuzzy modeling linguistic fuzzy rules in data mining: follow-up mamdani fuzzy modeling principle," no. January 2014, 2012.

[9] A. Shakiba, m. R. Hooshmandasl, b. Davvaz, and s. A. S. Fazeli, "s-approximation spaces: a fuzzy approach," vol. 14, no. 2, pp. 127-154, 2017.

[10] V. N. O. V ak, "a note to interpretable fuzzy models and," vol. 13, no. 7, pp. 53-65, 2016. 